\title{
AUTOR IMPLÍCITO Y NARRADOR NO FIABLE EN FÁBULA ASIÁTICA (2016), DE RODRIGO REY ROSA: UNA DIALÉCTICA NEGATIVA
}

\author{
IMPLIED AUTHOR AND UNRELIABLE NARRATOR IN FÁBULA \\ ASIÁTICA (2016), BY RODRIGO REY ROSA: A NEGATIVE DIALECTICS
}

EMiliano Coello GutiérRez Universidad Nacional de Educación a Distancia (UNED) ecoello@flog.uned.es

Fecha de recepción: 05-11-2020

Fecha de aceptación: 15-07-2021

\section{RESUMEN}

El presente artículo analiza Fábula asiática (2016), la decimosegunda novela del autor guatemalteco Rodrigo Rey Rosa. Se trata de una obra interesante por estar ambientada en Tánger (ciudad literaria por excelencia) y porque inevitablemente alude a algunos de los deseos, zozobras y temores de la compleja época actual. Si lo antedicho no carece de importancia, podría aseverarse que Fábula asiática adquiere relieve, más bien, por cuestiones de técnica narrativa. En efecto, la novela propone varios itinerarios de lectura, según se tenga en cuenta la perspectiva del narrador no fidedigno o el punto de vista del autor implícito, su opuesto. Como ocurre con el resto de la narrativa del autor, el texto tomará vuelo no solo por lo que dice, sino también por lo que silencia, por lo que oculta, por orientarse, de manera inequívoca, hacia lo inefable.

Palabras Clave: Fábula asiática, Tánger, Rodrigo Rey Rosa, autor implícito, narrador no fidedigno

\section{AbStract}

The present article analyses Fábula asiática (2016), the twelfth novel by Guatemalan author Rodrigo Rey Rosa. It is an interesting work because of its setting in Tangier (a 
literary city par excellence) and its inevitable allusions to some of the desires, anxieties and fears of our complex present age. Important as these aspects may be, we could state that Fábula asiática becomes certainly relevant because of elements of narrative technique. Indeed, the novel proposes various reading itineraries, depending on whether we choose to consider the perspective of an unreliable narrator, or its opposite, the implied author's point of view. As in other works by the same author, the text grows not only because of what it says, but also because of what is silenced, hidden, and for being unequivocally oriented towards the unspeakable.

KeY WORDS: Fábula asiática, Tangier, Rodrigo Rey Rosa, implied author, unreliable narrator

\section{Résumé}

Le présent article analyse Fábula asiática (2016), le douzième roman de l'auteur guatémaltèque Rodrigo Rey Rosa. Il s'agit d'un ouvrage intéressant car il est situé à Tanger (ville littéraire par excellence) et parce qu'il évoque certains désirs, angoisses et craintes de l'époque complexe que nous traversons. Si ceci ne manque pas d'importance, on pourrait affirmer toutefois que Fábula asiática s'étoffe plutôt par des aspects en rapport direct avec la technique narrative. En effet, le roman propose plusieurs itinéraires de lecture, selon qu'on tient compte du point de vue du narrateur non fiable ou selon qu'on privilégie le point de vue de l'auteur implicite, son opposé. Comme il advient avec le reste de l'œuvre narrative de l'auteur, le texte prendra de l'envergure non seulement par ce qu'il dit, mais aussi par ce qu'il cache, par ce qu'il passe sous silence, pour s'orienter, en un mot, vers l'ineffable.

Mots Clefs: Fábula asiática, Tanger, Rodrigo Rey Rosa, auteur implicite, narrateur non fiable

Quel est le rapport entre l'œuvre d'art et la communication? Aucun. GILLES DELEUZE, Qu'est-ce que l'acte de création?

Erst in dem Doppelbereich / werden die Stimmen / ewig und milch. RAINER MARIA RILKE, Sonetos a Orfeo.

\section{PREMISA}

René Descartes, en sus célebres Meditaciones Metafísicas (1596-1650), estableció la famosa hipótesis del genio maligno, un ser no menos artero y engañador que poderoso, el cual podría usar toda su industria para burlar a los humanos. De esta suerte, podría pensarse que el cielo, el aire, la tierra, los colores, las figuras, los sonidos y las demás cosas exteriores no son sino ilusiones y ensueños, de los que Él se sirve para atrapar nuestra credulidad. Un rol parecido al de dicho ente falsario es el que desempeñará el autor implícito en Fábula asiática, de Rodrigo Rey Rosa. Esta instancia narrativa, de manera explícita, pero sobre todo subrepticia, pondrá en entredicho la palabra de los personajes y principalmente la del narrador, impidiendo que la realidad de la fábula adquiera consistencia. Tras la lectura de la 
novela, pasada por el tamiz del punto de vista del autor implícito, el lector tendrá ante todo la impresión de que el mundo referido (inspirado en el verdadero) carece de solidez y no es más, como cree la filosofía y la religión budista, que un espejo vacío ${ }^{1}$.

Fábula asiática es la decimosegunda ${ }^{2}$ de las novelas del autor guatemalteco y la segunda ambientada en Tánger, tras La orilla africana, que publicara en 1999. Esta ciudad fascina al escritor no solo por su diferente ritmo y costumbres, sino porque durante buena parte del siglo Xx se convirtió en un enclave predilecto de grandes escritores y artistas que eligieron vivir allí. Es el caso de Samuel Beckett, Henri Matisse, Jean Genet, Paul Bowles, Jack Kerouac, William Borroughs, Juan Goytisolo, Margarite Yourcenar, Truman Capote o Tennesse Williams, entre otros ${ }^{3}$. La novela de Rey Rosa tendrá interés no solo por mostrar el Tánger contemporáneo o por hacer referencia a las complejidades de nuestro mundo globalizado. Fábula asiática será especialmente interesante por cuestiones de técnica narrativa, como habrá de verse.

\section{AUTOR IMPLIÍCITO Y NARRADOR NO FIABLE EN FÁBULA ASIÁTICA}

En la novela de la que se hablará seguidamente se produce un juego metanarrativo por el cual el escritor mexicano Rubirosa (trasunto del autor real) ${ }^{4}$ escribe un artículo denominado «Fábula asiática» para el periódico español El País. En él, ante las preguntas de dos niñas acerca de qué caracteriza lo intrínsecamente humano (con respecto, por ejemplo, al comportamiento de un autómata), el autor desarrolla una historia que procede de la esfera de lo onírico. Cinco niños, perseguidos por una tropa de milicianos (probablemente del ISIS) hasta una playa del país sirio, desean subirse en una barcaza con el fin de huir de la muerte. Ocurre que solo hay lugar en la misma para tres de ellos, por lo que los pequeños deciden permanecer todos juntos en tierra, a pesar del enorme riesgo. Esa actitud solidaria y heroica, según Rubirosa, es la que define la especificidad de nuestra especie, es lo que hace de ella algo único y distinto.

Las prendas morales del escritor mexicano motivan que el marroquí Mohammed Zhrouni le legue tres casetes y un disco de memoria para que los convierta en novela. En ellos se habla de la infancia de Aldelkrim, hijo de Mohammed, quien ha sido llamado para altos designios. Su inteligencia privilegiada causa que los americanos se fijen en él y se lo lleven a Estados Unidos para realizar estudios de aerodinámica, astronomía y astronáutica. Allí, en la

\footnotetext{
1 El budismo podría haber llegado a la escritura de Rey Rosa a través de Borges, quien profesaba un sincero respeto hacia este culto. Ver BORGES y JURADO (1991): Qué es el budismo, Barcelona, Emecé. El propio Rey Rosa reconoce en una entrevista concedida al diario El País (3-8-2017): «El ejercicio de leer es una especie de meditación conversada, es la meditación de los occidentales. De adolescente me interesaba la filosofía oriental y la meditación, ese desapego del mundo», Entrevista a Rodrigo Rey Rosa: «Nos hemos rendido a la tecnología acríticamente» | Babelia | EL PAÍS (elpais.com), acceso 1-12-2020.

2 Si se considera Cárcel de árboles (1991) como novela, como creo que debe hacerse.

3 Ver MENDOZA, Javier: «Tánger, patria emocional y generación beat», El Mundo, 22-11-2014, Tánger, patria emocional y generación 'beat' I Cultura I EL MUNDO, acceso 10-11-2020.

4 Es una de las numerosas trampas que tiende la novela, que constituye un sistema de equívocos.
} 
Universidad de la Singularidad en Silicon Valley, conoce al griego Xenophon Galanis, otro joven genio. Estos dos muchachos, a pesar de su pasión por la ciencia y la tecnología, poseen una visión del mundo muy anclada en lo religioso. Debido fundamentalmente al influjo de su padre, Abdelkrim posee un conocimiento acabado de la fe islámica, mientras que Xeno, cuya familia habita cerca del monasterio de San Juan el Teólogo en la isla de Patmos, ha estudiado los textos bíblicos en su idioma original, el griego antiguo, desde su más tierna infancia. Xeno y Aldelkrim, además de su formación teológica, poseen una gran sensibilidad social (no obstante que Xeno pertenezca a una familia de extraordinaria riqueza). Los acontecimientos de un mundo a la deriva (marcado por el terrorismo, la banalidad, los dramas humanitarios y las tremendas y crecientes desigualdades sociales) ocasionan que, junto al astrónomo de origen maya Matías Pacal, decidan intervenir. Es entonces cuando determinan asestar un golpe mortal al corazón del poder en nuestro mundo contemporáneo: la tecnología. Xenophon Galanis concibe, por consiguiente, el siguiente plan:

Su proyecto, su misión, era crear tres vastos anillos de destrucción alrededor de la Tierra. Una nave estacionada en uno de los Puntos de Lagrange (donde un objeto pequeño, afectado solo por la gravedad, puede mantenerse estacionario respecto a dos cuerpos más grandes, como la Tierra y la Luna) podría hacer el trabajo que Xeno vislumbraba: un pequeño apocalipsis tecnológico en las órbitas bajas y medias y, finalmente, en la geoestacionaria. (RODRIGO REY ROSA, 2016: 101)

La idea de los tres astrónomos es inutilizar los satélites de comunicación, provocando de este modo un caos tecnológico que retrotraería el planeta a una etapa de civilización anterior, donde los desequilibrios y las injusticias económicas, políticas y sociales serían menores. La novela termina en el museo Özkaya de Estambul, donde los «terroristas» han montado la nave, dotada con láser, que habrá de llevar a efecto la labor de exterminio. Dicha aeronave despega, con Rubirosa dentro, el cual habrá de dejar constancia de todo posteriormente en un monasterio de la isla de Patmos, una vez que se haya producido la «apocatástasis», es decir, el retorno de todas las cosas a su primitivo punto de partida.

Esta es la versión de los hechos que nos entrega Rubirosa, el escritor mexicano, la cual posee un sesgo religioso y sociopolítico (acaso sean la misma cosa) muy patente. Sin embargo, existen pruebas textuales suficientes para pensar que dicho testimonio de lo acontecido carece de fiabilidad ${ }^{5}$, y aquí es donde adquiere encarnadura textual un autor implícito opuesto en todo caso a la palabra del narrador principal que cuenta la historia o transcribe lo dicho por los personajes. Este autor implícito operará a todos los niveles, desde el paratextual hasta el propiamente narrativo o diegético. Vale la pena citar aquí la definición que hace Graciela Reyes de dicho concepto:

\footnotetext{
5 Acerca de la diferencia entre los conceptos de autor implícito y de narrador no fiable o no fidedigno son muy esclarecedoras las palabras del teórico Seymour Chatman cuando afirma: «La diferencia es especialmente evidente en el caso del «narrador no fidedigno» (otra de las felices creaciones de Booth). Lo que hace a un narrador no fidedigno es que sus valores divergen notablemente de los del autor implícito; es decir, el resto de la narración -«la norma de la obra»- entra en conflicto con la presentación del narrador y empezamos a sospechar de su sinceridad o competencia para contar la «versión verdadera». El narrador no fidedigno prácticamente se contradice con el autor implícito, de otro modo no sería aparente su condición de no fidedigno» (CHATMAN, 1990: 160).
} 
El autor implícito es el autor tal como se muestra, se construye, o se denuncia en su obra, pero es también, más estricta y menos dramáticamente, el conjunto de normas sobre las cuales está construida la obra, el «conjunto de elecciones» — de temas, de técnicas, de puntos de vistaque hacen de la obra lo que es: en este sentido, el autor implícito es coexistente con cada fragmento de su obra, con cada palabra, con cada destino ficticio, y con todo el sistema de ideas que da coherencia al conjunto de entidades o individuos ficticios. (GRACIELA REYES, 1984: 104)

La misma autora afirma: «otorgarle una voz diferente y distinguible, la de la ironía, por ejemplo, no me parece un pecado de lesa ficción. Propongo definir al autor implícito desde una doble perspectiva: en cuanto voz citada y en cuanto figura del autor» (GRACIELA REYES, 1984: 103) ${ }^{6}$. Es precisamente lo que ocurrirá en nuestra obra: esta voz y perspectiva autorial (que no es la del autor efectivamente existente) manifestará de diversos modos su divergencia con respecto a la visión de los hechos que aportan tanto los personajes en cuanto narradores como el escriba oficial de la fábula, Rubirosa, que está presente en la misma y la redacta, tras el «apocalipsis» tecnológico, desde el retiro de Patmos, en clara referencia al apóstol San Juan.

\subsection{Los paratextos}

En la esfera propiamente paratextual, todos los elementos ejercen la función de des-realizar el significado y el mensaje de la novela. El título, Fábula asiática, tiene un sentido literario y religioso evidente, si se tiene en cuenta que las grandes religiones monoteístas (y el budismo, no se olvide) tienen su origen en el continente asiático. El islam y el cristianismo estarán muy presentes en nuestra obra por medio de los personajes de Abdelkrim y de Xenophon Galanis. Y la labor del autor implícito supondrá que la realidad referida tenga más la apariencia de un sueño que de algo verdadero. En el libro La ley del Buddha entre las aves, guirnalda preciosa, texto prototípico de la doctrina budista, se dice: «Mientras viváis en este mundo del Samsara, / no tendréis dicha duradera. / La ejecución de asuntos mundanales / no tiene fin. / En la carne y en la sangre / no hay permanencia. / Mara, Señor de la Muerte, / nunca está ausente. / Dondequiera que miréis, / nada substancial hay allí. / ¿Me comprendéis?» (BORGES, 1991: 116).

La portada del libro (en su edición de Alfaguara 2016) reproduce una fotografía de Pedro Albornoz, que retrata el puerto de la ciudad marroquí de Essaouira. A lo lejos, pueden

6 Será útil recordar que en Fábula asiática la existencia del autor implícito puede estar dotada de voz, aunque en la mayor parte de los casos solo consta de perspectiva y es, por tanto, una presencia muda. El dictum autorial se evidencia sobre todo en la primera parte de la novela, en la sección titulada «El futuro de Abdelkrim», centrada en el testimonio del padre del muchacho que aspira a ser astronauta, Mohammed Zhrouni. Por ejemplo, en el encuentro de Mohammed con John Field (capítulo primero) se alude a la vestimenta del norteamericano y aparece el siguiente comentario, a modo de aparte: «Mohammed pronunciaba sida» (2016: 21). O cuando se habla del encuentro maravilloso de Mohammed con un ave mensajera (capítulo segundo), y se dice: «¿o había dicho 'espacial'?» (2016: 27). Naturalmente, estas palabras no pueden proceder de Mohammed ni del narrador encargado de redactar y dar a la estampa su historia, el escritor mexicano (que tiene una relación de amistad fraterna con los personajes), sino que han de provenir del autor implícito. 
observarse algunos edificios de arquitectura típica del lugar, pero la mayor parte del espacio la ocupa el cielo. En primer plano puede verse una gaviota cuya imagen aparece difuminada. La impresión que produce el conjunto es la de un ambiente vagaroso, propicio a la fantasía y a la ensoñación.

Las citas que preceden cada una de las partes de la novela (que son tres) también están sabiamente seleccionadas. La primera de ellas procede del primer libro de la Historia verdadera de Luciano de Samosata. Será provechoso reproducirla completa:

Vi otra maravilla aún en el palacio real. Era un espejo grande colocado encima de un pozo medianamente profundo. Al bajar a este pozo podía oírse todo lo que los hombres y mujeres dicen en la Tierra, y al alzar los ojos uno podía ver todas las ciudades y todas las aldeas, como si uno se encontrara ahí entre ellos. (REY ROSA, 2016: 9)

No se olvide que en este primer libro de los Relatos verídicos (o Historia verdadera) el narrador nos habla desde la Luna (donde tiene un encuentro con los «cabalgabuitres» y con el rey Endimión), batalla contra el Sol por la Estrella de la Mañana y describe la naturaleza sorprendente de los selenitas. Los quehaceres del mundo, de nuestro mundo, se observan, pues, a gran distancia. La alusión a un espejo (donde los seres y las cosas pueden verse y oírse, pero carecen de tangibilidad) refiere a que los asuntos mundanos no van más allá de la esfera de la apariencia (esta misma perspectiva filosófica puede colegirse del accionar del autor implícito en Fábula asiática).

La segunda parte de nuestra obra se abre con una cita de la Wikipedia (26/06/2016 a las 11h) que dice: «Jenofonte tiene defectos notables: no es exhaustivo en la recolección de datos, es olvidadizo y margina hechos de primera importancia. Cuenta las cosas desde su propia perspectiva» (2016: 75). La lectura que puede hacerse de dichas palabras es que no existe una verdad objetivamente cuantificable, como afirma la historia del pensamiento y del arte desde Kant, sino que la realidad es más bien producto de la visión que nosotros tenemos de ella, y en tal sentido es puramente subjetiva.

Por último, la tercera parte de Fábula asiática aparece precedida de una cita procedente del cuento Micromegas (1752) de Voltaire, que ha sido considerado como una de las primeras obras de ciencia ficción. En dicho fragmento se habla de la principal ocupación de la raza humana: «en este momento en que te hablo hay cien mil locos de nuestra especie, sus cabezas cubiertas con sombreros o con cascos, que matan a otros cien mil brutos, sus cabezas cubiertas con turbantes, o que se dejan matar por estos» (2016: 121). Hay que recordar que en este cuento fantástico se describe la visita a la tierra de un ser (de ocho leguas de alto) originario de un planeta que gira en torno a la estrella Sirio llamado Micromegas, y de un compañero suyo, también gigantesco, procedente del planeta Saturno. Los humanos, en comparación con estos colosos, poseen una talla microscópica. Tanto los Relatos verídicos de Luciano de Samosata como el Micromegas volteriano transmiten la convicción de que, a escala universal, los trabajos y preocupaciones que aquejan a los hombres son extremadamente pequeños (la mirada externa y extrañada del narrador, en ambos casos, los dota de su relevancia real). El punto de vista del autor implícito de Fábula asiática también se hará eco de esta lejanía, hasta el punto de que en ocasiones su discurso puede percibirse como «inhumano» $\mathrm{o}$, al menos, como deshumanizado. 


\subsection{Rubirosa: un narrador no fiable}

Los argumentos que sustentan la existencia de un punto de vista autorial (que campea en el relato, por encima de las demás voces) tienen que ver fundamentalmente con el retrato que en la obra se hace del personaje del narrador, el escritor mexicano de nombre Rubirosa $^{7}$. En todo momento se le presenta como especialmente afecto al kif ${ }^{8}$. En el capítulo cinco de la primera parte (sección «El futuro de Abdelkrim»), en que el pintor John Field recibe en su casa a visitantes de varias nacionalidades (estadounidense, francesa y alemana) que vienen a ver sus cuadros, el marroquí alude de la siguiente forma al novelista mexicano: «estaba ya muy fumado, y yo» (2016: 42). En el capítulo uno de la tercera parte (sección «Sudario») también se afirma: «Aunque fumar podía poner un poco paranoico al Mexicano, quería llevar a cabo una vez más el ritual norteafricano» (2016: 146). En los capítulos quinto y octavo de esta sección pueden constatarse dos referencias más a la adicción del narrador: «¿no quieres fumar? Por qué no - contestó sin pensarlo; fue un error: no necesitaba en aquel momento otro inductor de paranoia» (2016: 163). Y «El hábito pudo más que la razón, y se preparó otra pipa de kif» (2016: 173).

La visión de Rubirosa de la que disponemos en la primera parte de Fábula asiática está influenciada por la perspectiva de Mohammed, para quien el mexicano es alguien caracterizado por un temperamento distraído, e incluso, podría decirse, no muy avispado: «El mexicano, a mi derecha, no decía nada. Sus ojos iban de un hablante a otro y, si no les entendía, era como si quisiera captar lo que decían con la mirada. Le ofrecí de fumar y aceptó» (2016: 41). Y «El mexicano había vaciado ya su taza de té. Me reí de él» (2016: 45).

En lo tocante a la forma de pensar del narrador «oficial» de la historia, se produce un episodio esclarecedor en los capítulos cinco y seis de la primera parte (sección «El futuro de Abdelkrim»). Resulta que Mohammed discute con un profesor bostoniano acerca de la fuente de la auténtica sabiduría. El occidental defiende los libros y la cultura, mientras que Mohammed alude al corazón como lugar depositario del auténtico saber, procedente de la divinidad. La escuela no sería otra cosa, según el pensamiento del marroquí, que un lugar inductor de problemas. En ese momento, Rubirosa se apresura a darle la razón, aunque ello suponga ir en contra de su propia idiosincrasia cultural: «Boko haram — dijo, sonrienteEs verdad» (2016: 47).

Sabemos que el escritor mexicano es el personaje elegido por Mohammed Zhrouni para componer un libro con los tres casetes y el disco de memoria que le entrega. En este segundo aparecen textos en árabe clásico, compuestos por Abdelkrim, en los cuales se

7 Es muy significativo que Rubirosa, a pesar de haber participado en los hechos que forman parte de la diégesis, no haya elegido la primera persona para escribir Fábula asiática, sino que sea la tercera persona (que se aleja de la identidad y del testimonio del mexicano) la que señoree claramente en el relato. Ello es debido a que la figura del autor implícito ha suplantado la voz del narrador testigo.

8 Debe afirmarse que la presencia de esta droga, el kif o hachís, atraviesa la novela de punta a cabo, hasta tanto que apenas hay personaje en ella que no lo consuma. Lo toman Mohammed y su hijo, el pintor estadounidense John Field, Xeno Galanis, el astrónomo maya Matías Pacal, y por supuesto el narrador, a quien ninguno de ellos aventaja. 
comentan pasajes del libro sagrado de los musulmanes. Aun así, al Mexicano no se le ocurre otra cosa que recurrir para la traducción de los mismos a David Singer, a pesar de los rumores que sobre él circulan en la ciudad:

Solían decir en Tánger que una de las tradiciones de los servicios secretos norteamericanos era tener un agente a la cabeza de la Antigua Legación Americana, que está en la parte baja y oriental de la Medina. Aquel año, el director no era una excepción. David Singer (un metro noventa, fornido, calvo, macrocéfalo) era una proyección de Graham Greene, pensó el Mexicano cuando los presentaron (2016: 123).

Aunque el escritor mexicano no podía saber en aquel momento en qué consistían los planes de Abdelkrim (en connivencia con sus amigos y compañeros Xeno Galanis y Matías Pacal), no parece muy buena decisión entregar unos escritos en árabe a un espía estadounidense, comoquiera que se mire. Esta torpeza es la que ocasionará la paranoia del narrador en las dos primeras secciones de la tercera parte, que es cuando Rubirosa se cree accidentalmente entremetido en las discordias de dos molosos en liza, el norteamericano y el musulmán. Es entonces cuando cambia de vestimenta (le compra una chilaba a un vendedor ambulante), se muda de hotel, esconde la computadora debajo de su ropa de calle, evita a David Singer e incluso utiliza un lugar algo extraño para salir del Grand Hotel Villa de France donde se hospeda, protagonizando una escena de indudable comicidad:

Una cadena y un candado impedían el paso por la verja; se acomodó la espuerta en un hombro y comenzó a trepar. Shni bgrit? —oyó a sus espaldas. Volvió la cabeza. Era un viejo jardinero. No lo conocía. No puede hacer eso, sidi. El Mexicano no conseguía hacer pasar la pierna por encima de las lanzas. Baje de ahí, hombre. Obedeció. El jardinero recibió la espuerta para ayudarle a bajar. Smaheli. Disculpe — le dijo el Mexicano—. Tengo que salir... Blati. Se sacó de un bolsillo una llave grande y oxidada para abrir el candado. La verja se abrió con un chirrido. Shukran b'sef! La shukran. Al-láh wa shib. (2016: 155)

La sensación de ser un chivo expiatorio que invade a Rubirosa durante toda la novela procede del hecho de que en todo momento tiene un conocimiento deficiente de lo que acontece (siempre sabe menos que el resto de los personajes y que el lector, por lo que su estatuto es necesariamente risible), y no es sino al final cuando adquiere entera noticia de lo que proyectaron Abdelkrim y sus compañeros (entre los que se encuentra Nada, la hermana de Xeno). Se apercibe de todo cuando los «terroristas» lo han subido a empellones a la aeronave que ha de ocasionar el fin del mundo tal y como lo conocemos:

Se podría generar una reacción en cadena que transformara la órbita de la Tierra en un derbi de demolición —explicó ella mecánicamente, mientras acababa de abrocharse el traje (...). Una vez neutralizados los satélites — decía ella—, transmitiremos nuestro mensaje. Nick y otra parte del equipo están ocupándose de los cables transoceánicos y de AT\&T, GAFAM (Google, Amazon, Facebook, Apple, Microsoft) y sus rivales, que son el gran enemigo en ese aspecto (...). Cuando hayamos terminado la tarea, volveremos a la isla de Leros a socorrer migrantes, que no paran de llegar, a pesar de las nuevas leyes. ¿Te parece? Nadie nos buscará allí. (2016: 200) 


\subsection{Místicos e/o iluminados}

La estampa de los demás personajes que nos entrega el autor implícito también está salpicada de ironía. Y en este punto se utilizan diferentes técnicas narrativas. En un par de ocasiones a lo largo de la novela se usa un recurso cinematográfico del que hablara Gilles Deleuze cuando se ocupó del séptimo arte, a saber, la disociación (y a un mismo tiempo la imbricación) entre imagen y sonido:

je parlerai de la fameuse dissociation Voir/Parler dans un cinéma relativement récent. Je prends les cas les plus connus, que ce soit Syberberg, que ce soit les Straub, que ce soit Marguerite Duras, qu'est-ce qu'il y a de commun? Voyez, en quoi c'est proprement cinématographique : faire une disjonction du visuel et du sonore (...). On parle de quelque chose et en même temps on nous fait voir autre chose. Et enfin ce dont on nous parle est sous ce qu'on nous fait voir et c'est nécessaire, sinon les deux premières opérations n'auraient aucun sens, elles n'auraient guère d'intérêt. (Qu'est-ce que l'acte de création? par Gilles Deleuze sous-title français / sub. French - YouTube, acceso 28-11-2020)

Esto es precisamente lo que ocurre en los capítulos segundo y tercero de la primera parte de la novela (sección «El futuro de Abdelkrim»). En ambos puede verse a Mohammed solo. En el primer caso, se retira del ritual de circuncisión de su hijo; en el segundo, se va a pescar. En las dos ocasiones se produce una especie de parodia de la famosa escena bíblica de la Anunciación, solo que esta vez, en lugar de recibir la visita de un arcángel, al personaje se le aparece un cuervo, que le transmite la buena noticia: su hijo menor, Abdelkrim, fue escogido por la divinidad para hacer grandes trabajos. Su familia deberá servirle como si fuera su señor, porque él tendrá poder sobre ella y sobre toda su raza. Esto es lo que se oye. Sin embargo, lo que se ve es muy diferente. El propio Mohammed reconoce que «la luz tiembla todo el tiempo cuando fumas» (2016: 33). De modo que lo que se escucha (el episodio religioso o pseudoreligioso) aparece disociado de lo que se ve (al personaje consumiendo kif) y al mismo tiempo lo auditivo se incrusta por debajo de la visión de Mohammed en dicha tesitura. El temblor de la imagen parece causado por el trance místico, pero es un efecto engañoso.

Una parecida disyunción entre imagen y sonido tiene lugar en los capítulos seis y ocho de la segunda parte de la obra, aquellos en que asistimos a una cena «buñueliana» que la familia Galanis ha organizado para conmemorar el doctorado de su vástago, Xeno. Los invitados al evento son veintidós, entre los que se encuentran princesas, ministros, industriales y demás. Si hay algo que todos tienen en común es que son inmensamente ricos. Este fasto es el que se ve. No obstante, lo que se oye es muy diferente, pues se pasan el banquete hablando de la situación de los refugiados y haciendo planes con los que arreglar los problemas del mundo. El resultado de esta mezcla no deja de ser surrealista.

En lo concerniente al personaje de Xeno, principal artífice del plan que pretende poner en práctica en nuestros días el concepto teológico de «apocatástasis», la novela también es ambigua. El autor implícito elige para la caracterización del joven griego la técnica narrativa del estilo indirecto libre, en la cual se produce una confluencia entre el punto de vista del narrador y el del personaje, pero manteniendo la distancia. Diríase que la voz que cuenta se introduce en la mente del personaje (el imperfecto con valor 
de presente y las referencias deícticas actualizan lo mentado), pero al mismo tiempo se impone una lejanía (lograda gracias al uso de la tercera persona y al empleo del tiempo pasado). Será conveniente mostrar aquí completo el pasaje del capítulo cuarto de la segunda parte en que Xeno Galanis se autoconvence de la necesidad de pasar a la acción para desembarazar al mundo de un periodo (que estima inacabable) de degeneración y decadencia moral:

Todos los actos — los buenos, los malos, aun los actos indiferentes- tenían un efecto doble. ¿Cuál era el objetivo de sus acciones últimamente? Sintió de pronto, con la fuerza de una revelación, que tenía un trabajo especial que llevar a cabo durante su estadía en la Tierra. Y la piel se le erizó con una sensación que rayaba en lo voluptuoso, seguida de un escalofrío. ¿Era el espíritu del otro, que acaba de morir, que había entrado en él? El ritmo de su andar le infundía ánimo, y el declive favorable eliminaba la posibilidad de cansancio. Quizá pecaba de arrogante; quizá para sentir lo que sentía era necesario ver las cosas desde su posición elevada. «No hay que esperar que el Señor venga de la tierra, sino del cielo», había escrito Juan en su libro. ¿No podía Xeno, dos mil años más tarde, transformar su propio mundo — desde el cielo? ¿Era imposible, se preguntó a sí mismo mirando el mar desde un recodo del camino, vencer de vez en cuando el mal? Abajo estaba un palomar desvencijado, varias palomas zureaban y revoloteaban por allí. Debía ser posible terminar, al menos con la violencia física. (El sufrimiento era otra cosa y quizá eso no podía tener fin). Algo así debieron de sentir Buda, Jesús, tal vez incluso Marx. (2016: 98)

Puede observarse que la utilización del estilo indirecto libre vehicula en este caso un punto de vista irónico acerca del personaje, tocado por el fanatismo religioso y la megalomanía? .

En cuanto a Abdelkrim, la disociación viene entre lo expresado por el personaje en la tercera sección de la primera parte (denominada «Aljamía») y lo que, poco tiempo más tarde, realiza. En las cartas dirigidas a sus padres, se muestra entusiasmado con la cultura occidental e incluso está dispuesto a conciliar la cultura islámica y la cultura del progreso a la norteamericana, como muestra el siguiente fragmento:

Como le dije a Yimma hace unos días por Skype, yo y otros veintitantos estudiantes fuimos seleccionados entre miles de aspirantes para seguir un programa especial de la NASA. En pocos meses más, nacionalización mediante, nos habremos convertido en auténticos astronautas. (Es posible que me den la nacionalidad honoraria, por ser un «Alien of extraordinary ability». Así se la dieron a Albert Einstein y a otros aliens). ¿Recuerdas, Yimma, cómo Ba decía que eso de que el hombre había puesto los pies en la Luna era una mentira, propaganda de los americanos, que querían igualarse a Dios para ser admirados por encima de todos los hombres? Quienes aseguran tales cosas están equivocados. ¡Alá nos hizo inteligentes y audaces y capaces de grandes obras porque le place ver cómo sus criaturas pueden reconocer y conquistar no solo la bola del mundo sino todo el Universo! (2016: 67)

9 Respecto de Xeno, hay un episodio en el capítulo segundo de la segunda parte que proporciona información valiosa sobre su personalidad, y que preludiará en cierta forma lo que vendrá después. De pequeño, frecuentaba a los monjes de las islas griegas y, como tenía inquietudes científicas, pensó que en épocas lejanas los religiosos de los monasterios de Constantinopla, Jerusalén y Roma se comunicaban entre sí con celeridad mediante un sistema de alarmas basado en señales de humo (páginas 84-86 de nuestro texto). Dada la enorme distancia entre esas tres ciudades, parece una idea cuestionable. 
Sin embargo, cuando los Estados Unidos le niegan la nacionalidad, un cambio se opera en su interior, y termina radicalizándose. Lo chocante del caso es que su ulterior rechazo a la civilización occidental no proviene de una íntima convicción, sino del resentimiento por no haber podido cumplir su sueño de llegar a convertirse en el primer astronauta marroquí.

\subsection{Opera chiusa e opera aperta}

Incluso la estructura de la novela puede ser leída de forma diferente si se hace desde el punto de vista del narrador 'oficial' de la obra o si se lee desde la perspectiva que propone el autor implícito. En Fábula asiática existen tres partes, la primera de ellas contiene tres secciones («El futuro de Abdelkrim», «Buyulud»y «Aljamía»), la segunda de ellas posee solo una sección («Jenofonte») y la tercera incluye de nuevo tres secciones («Infección», «Sudario» y «Joyride»). En la primera parte, centrada en personajes musulmanes (fundamentalmente Mohammed y Abdelkrim), se habla de la infancia de este último, un muchacho superdotado, y de una profecía que augura que el entonces niño se convertirá en un líder de su raza. En esta primera parte también hay que notar que el padre de Abdelkrim tiene que recurrir en todas las ocasiones (el bautizo, la circuncisión y la enfermedad de su hijo) al norteamericano John Field para que le preste dinero, por su gran pobreza. Esto puede crear una suerte de resquemor en su espíritu (que heredará su hijo). También es notorio el malestar que le provoca a Mohammed todo lo que proceda de los «nazara», es decir, de la civilización occidental.

En la segunda parte, centrada en el personaje de Xeno, puede observarse que se trata de un chico que no es como los demás, pues desde su más tierna infancia muestra un vivo interés por la cultura, sobre todo la teológica, hasta el punto de que los monjes de las islas griegas creen que se trata de un santo. Pese a haber crecido en una familia inmensamente rica, ya de pequeño le toca acompañar a su padre, médico, en las labores de acogida y curación de los inmigrantes y refugiados enfermos, por lo que entra en contacto con la injusticia y el mal en el mundo. En esta segunda parte es cuando se habla del vínculo entre Xeno Galanis, Abdelkrim Zhrouni y Matías Pacal, que forman parte de la elite científico-técnica estadounidense. En una visita de los tres muchachos a Tassajara, se urde el plan que pretende frenar la desigualdad en el mundo.

Y en la tercera parte nos encontramos en el museo Özkaya de Estambul, donde la gente de Xeno y Abdelkrim monta la aeronave que habrá de llevar a cabo el desorden tecnológico y la «apocatástasis». Puede verse, pues, que se trata de una estructura tripartita clásica, formada por un planteamiento (profecía y desprecio hacia el progreso técnico-científico proveniente de Estados Unidos), un nudo o desarrollo (aquí adquiere protagonismo la figura del genio griego que diseña el plan de ataque, asqueado por la falta de equidad en el mundo) y un desenlace (ejecución del proyecto y salvación de la raza humana). Se trata de una estruc-tura que sigue la lógica de causa-efecto.

No obstante, si bien se mira, esta aparente solidez de la estructura de la obra se resquebraja a poco que se tenga en cuenta que el asunto principal de la misma, la fabricación de un dispositivo que logre destruir en un breve lapso todo el sistema satelital que orbita 
alrededor de la Tierra, apenas ocupa un par de párrafos en el capítulo quinto de la segunda parte $^{10}$. Podría concluirse, por ello mismo, que toda la novela, hasta llegar a la tercera sección de la tercera parte, denominada «Joyride», no ha sido más que una fabulosa y extensa $\operatorname{digresión}^{11}$.

A más de esto, tanto el desenlace como el cierre de nuestra novela trastocan el «evangelio» del Mexicano, según el cual la transformación del mundo llega a materializarse. Téngase en cuenta que en el capítulo sexto de «Sudario» (en la tercera parte), Abdelkrim le dice a Rubirosa: «Confiamos en ti. Necesitamos que alguien escriba nuestra historia, aun si fracasamos. Sobre todo, si fracasamos» (2016: 169). Y que el relato se cierra con estas palabras:

En la terraza del magnífico museo las miradas de todos —asiáticos, europeos, africanos, americanos y quizá también oceánicos- fueron fijadas por un suceso extraordinario. La nave, pequeña como una avioneta, volando hacia lo alto, pareció inflamarse en el aire y trazó un surco de llamas que se desvanecía en el espacio, a la manera de una estrella fugaz, arrastrando detrás de ella una larga cabellera luminosa. Todos exclamaron. Exultante, Xeno se volvió hacia Nick, que miraba el cielo con una flauta de champán en una mano, y lo abrazó con gozo - como Eneas había abrazado a Acestes, escribiría más tarde, en paz (sin teléfono, sin internet), en Patmos, el afortunado Mexicano, cuando ya los horrores y portentos narrados aquí se habían convertido, momentáneamente, en cosas del pasado. (2016: 203)

Tras la lectura del párrafo, el lector, perplejo, no sabe si está asistiendo al principio del apocalipsis o a una atracción de feria, del mismo modo que no puede saber si el «apóstol» que redacta lo acontecido transmite un suceso de extraordinarias dimensiones (sociopolíticas y económicas) o más bien se hace eco de las fantasías de un grupito de muchachos extravagantes con ínfulas mesiánicas.

\section{CONCLUSIÓN}

Más allá de las citadísimas palabras de Roberto Bolaño sobre el autor guatemalteco ${ }^{12}$, habría que afirmar que Rodrigo Rey Rosa es un autor que se nutre de los más diversos géneros narrativos y de distintas y heterogéneas tradiciones culturales (la occidental, por supuesto, pero también la indígena e incluso la asiática), de ahí su enorme originalidad, que no tiene paralelo, no solo entre los escritores de su generación, sino, quizá, entre los escritores de nuestro idioma.

10 Por otro lado, la idea que tiene Xeno de situar su aeronave en los puntos de Lagrange, lugar desde donde se ejecutaría el ataque, parece, asimismo, de difícil realización (baste decir que el punto L1, por ejemplo, dista 1.502. 000 kilómetros de nuestro planeta). El punto de vista del autor implícito ironiza aquí, posiblemente, acerca del interés por los viajes espaciales que existe en la actualidad.

11 Las dos primeras secciones de la tercera parte («Infección» y «Sudario»), ancladas en la paranoia de Rubirosa, la cual tiñe el relato de un humorismo absurdo, confirman lo dicho.

12 El novelista chileno se expresó de él en estos términos: «Decir que Rodrigo Rey Rosa es el escritor más riguroso de mi generación y al mismo tiempo el más trasparente, el que mejor teje sus historias y el más luminoso, no es decir nada nuevo», Descontexto: «Rodrigo Rey Rosa en Mali, creo», de Roberto Bolaño, acceso 4-1-2021. 
En Fábula asiática se nos ofrece una novela dual que posibilita diferentes lecturas, según se escoja el punto de vista del escriba «oficioso» de los hechos, Rubirosa, o la forma de ver el mundo que sugiere el autor implícito, una instancia narrativa que maneja todos los hilos del relato, desde los paratextos a lo textual propiamente dicho. El Mexicano, a petición de los personajes místicos de la novela (a saber, Mohammed, Abdelkrim y Xenophon Galanis), nos entrega una versión de lo ocurrido marcada por la crítica social, el apocaliptismo y un repudio evidente hacia el culto al progreso propio de nuestra era tecnocéntrica.

Contrariamente, la mirada del autor implícito, que adopta una óptica signada por el escepticismo, se alejará de cualquier conato de trascendencia, ya provenga esta de la esfera teológica o de cualquier sucedáneo actual de la religión. El enfoque del genius malignus está definido en Fábula asiática por el desapego hacia lo mentado, que no se considera más que como un teatro de apariencias. Así, las citas que jalonan cada parte de la novela tienen como función lograr que el lector se sitúe en una posición diferente de la consuetudinaria, para que desde ella juzgue de otro modo los negocios del mundo (a los que habitualmente se concede tanta importancia).

El designio del autor implícito pone en práctica diversas técnicas para alejarse del dictum y de la identidad del narrador y de los personajes, los cuales pretenden materializar, en nuestros días, un retorno a la pureza del origen. El narrador se nos presenta como un escritor (y aun un ciudadano) no fidedigno, por múltiples razones. Por su parte, el punto de vista autorial se sirve de distintos recursos para explicitar el alejamiento con respecto a Mohammed, a Xeno o a Abdelkrim. La técnica cinematográfica plasmará la contradicción entre lo que se profiere y lo que se observa, mientras que el estilo indirecto libre le servirá a la figura autorial para adentrarse en la intimidad de Xeno, al tiempo que se distancia, con una refracción irónica, de su cosmovisión alucinada.

Incluso la estructura del relato es equívoca, según se observe desde un ángulo o desde el otro. La disposición tripartita es deudora de una idea de causalidad clásica e incluso de un sentido analítico (por cuanto las diversas tradiciones y formas de pensamiento se amalgaman y sintetizan en la ofensiva final). Por el contrario, debido a la enorme ambigüedad del desenlace y el cierre de la obra, dicha asertividad y facticidad también pueden transformarse en un espejismo.

En último término reside en el lector implícito la responsabilidad de tener en cuenta las sugerencias que le ofrece su contraparte autorial (deshumanizada, descreída), o bien oscilar hacia la «buena noticia» que transmite Rubirosa (fideísta). También puede optar por no otorgar crédito a ninguno de esos dos extremos. ¿Son acaso diferentes? Viene aquí a la memoria la lección ontológica de Jorge Luis Borges: el otro puede ser el mismo, es decir, la plenitud puede albergar el vacío.

Si, como avizoró Gilles Deleuze, la comunicación y por ende la información no es más que un sistema codificado de consignas o de órdenes ${ }^{13}$, mediante los cuales el conocimiento

13 El filósofo francés aseveraba: « en un premier sens, on pourrait dire que la communication, c'est la transmission et la propagation d'une information. Or, une information, c'est quoi ? Ce n'est pas très compliqué, tout le 
se transforma en acto (dirigido), entonces la literatura y el arte en general tienen poco que ver con los aspectos comunicativos. La narrativa de Rodrigo Rey Rosa, que posee la característica de 'literaria' en grado sumo, se caracteriza por la creación de autores implícitos que subvierten en todas las ocasiones las máximas pragmáticas e informativas de cantidad, calidad, relación y manera. Por esa razón el valor comunicacional de sus textos es muy bajo, mientras que la calidad expresiva de los mismos es enorme. La literatura del autor guatemalteco se sirve de la palabra para mostrar siempre su frontera, es decir, aquello que está más allá de la taumaturgia del verbo, a saber: le non-dit. Su obra se encauza hacia lo que está allende lo humano, que puede ser el silencio, la vacuidad o la noche. Debido a ello, sus obras resisten, en un doble sentido: perduran, y ofrecen resistencia a lo dado.

\section{REFERENCIAS BIBLIOGRÁFICAS}

Adorno, Theodor (2005): Dialéctica negativa. La jerga de la autenticidad, Madrid, Akal.

Anónimo (2009): La Ley del Buddha entre los pájaros, Palma de Mallorca, José J. de Olañeta Editor.

BARTHES, Roland (2012): El grado cero de la escritura (seguido de Nuevos ensayos críticos), Madrid, Siglo XXI.

Bauman, Zygmunt (2007): Tiempos líquidos. Vivir en una época de incertidumbre, Barcelona, Tusquets.

- (2015): La globalización. Consecuencias humanas, México, Fondo de Cultura Económica.

Booth, Wayne C. (1961): La retórica de la ficción, Barcelona, Bosch.

Borges, Jorge Luis y Jurado, Alicia (1991): Qué es el budismo, Buenos Aires, Emecé.

CAmus, Albert (1963): El mito de Sísifo. El hombre rebelde, Buenos Aires, Losada.

Chatman, Seymour (1990): Historia y discurso. La estructura narrativa en la novela y el cine, Madrid, Taurus.

Coello Gutiérrez, Emiliano (2008): «La narrativa breve de Rodrigo Rey Rosa: un vuelco a la racionalidad» (http://www.repositorio.ciicla.ucr.ac.cr:8080/123456789/261).

Culler, Jonathan (1984): Sobre la deconstrucción, Madrid, Cátedra.

Deleuze, Gilles (1983): L'image-mouvement, Paris, Éditions de Minuit.

— (1987) : «Qu'est-ce que l'acte de création ? », https://cutt.ly/ZjfoPQ5, acceso 21-10-2020.

Descartes, René (1977): Meditaciones metafísicas con objeciones y respuestas (introd. Vidal Peña), Madrid, Alfaguara.

D’haen, Theo (2015): «Latin American Literature Between World Literature and Géocritique», América Latina y la literatura mundial: mercado editorial, redes globales y la invención de un continente, ed. Gesine Müller y Dunia Gras, Madrid, Iberoamericana Vervuert, pp. 55-65.

\footnotetext{
monde le sait : une information, c'est un ensemble de mots d'ordre. Quand on vous informe, on vous dit ce que vous êtes censés devoir croire. En d'autres termes : informer, c'est faire circuler un mot d'ordre. Les déclarations de police sont dites, à juste titre, des communiqués ; on nous communique de l'information, c'est à dire, on nous dit ce que nous sommes censés être en état ou devoir croire, ce que nous sommes tenus de croire. Ou même pas de croire, mais de faire comme si l'on croyait, on ne nous demande pas de croire, on nous demande de nous comporter comme si nous le croyions. C'est ça l'information, la communication, et indépendamment de ces mots d'ordre, et de la transmission de ces mots d'ordre, il n'y a pas de communication, il n'y a pas d'information. Ce qui revient à dire : que l'information, c'est exactement le système du contrôle », Qu'est-ce que l'acte de création? par Gilles Deleuze sous-title français / sub. French - YouTube, acceso 28-11-2020.
} 
Eтte, Otмar (2015): «Desde la filología de la literatura mundial hacia una polilógica filología de las literaturas del mundo», América Latina y la literatura mundial: mercado editorial, redes globales y la invención de un continente, eds. Gesine Müller y Dunia Gras, pp. 323-367.

GARCía LANDA, José ÁNGEL (2011): «El autor implícito y el narrador no fiable según nuestro punto de vista (Implied Authors and Unreliable Narrators From Our Point of View)», https://cutt.ly/ujfr8dC, acceso 28-11-2020.

Ortega, Julio (2015): «La lectura trasatlántica. Un paradigma dialógico de la historia cultural latinoamericana», ed. Gesine Müller y Dunia Gras, pp. 21-29.

Paz Gago, José María (1993): «Texto y paratexto en el Quijote», Texto y paratexto en el «Quijote» (cervantes.es), acceso 22-11-2020.

Pollman, Leo (1973): Sartre y Camus. Literatura de la existencia, Madrid, Gredos.

Rey Rosa, Rodrigo (2016): Fábula asiática, Madrid, Alfaguara.

Reyes, Graciela (1984): Polifonía textual. La citación en el relato literario, Madrid, Gredos.

Steiner, George (2013): Lenguaje y silencio. Ensayos sobre la literatura, el lenguaje y lo inhumano, Barcelona, Gedisa.

Trías, Eugenio (2003): Lógica del límite, Barcelona, Círculo de Lectores. 